\title{
Pharmacokinetics, bioavailability and dose assessment of Cefquinome against Escherichia coli in black swans (Cygnus atratus)
}

\author{
Dong-Hao Zhao ${ }^{1,2,3,4}$, Xu-Feng Wang ${ }^{1,2,3,4}$, Qiang Wang ${ }^{1,2,3,4}$ and Liu-Dong Li, 1,2,3,4* $^{*}$
}

\begin{abstract}
Background: The objective of this study is to investigate pharmacokinetics and dose regimens of cefquinome in black swans following intravenous (IV) and intramuscular (IM) administration at a single dose of $2 \mathrm{mg} / \mathrm{kg}$. The MICs of cefquinome against 49 Escherichia coli isolates from black swans were determined. Monte Carlo simulation was applied to conduct the dose regimen assessment and optimization of cefquinome against E. coli in black swans, and a pharmacokinetic/pharmacodynamic (PK/PD) cutoff was established for E. coli isolates obtained in this study.

Results: The PK parameters of $T_{1 / 2 a}(0.31 \mathrm{~h}), \mathrm{T}_{1 / 2 \beta}(1.69 \mathrm{~h})$ and $\mathrm{Cl}_{B}(0.13 \mathrm{~L} / \mathrm{kg} \cdot \mathrm{h})$ indicated a rapid distribution and elimination of cefquinome in black swans after IV administration. After IM injection, the corresponding PK parameters of $T_{1 / 2 \mathrm{Ka}}, T_{1 / 2 \mathrm{Ke}}, T_{\max }, C_{\max }$ and $\mathrm{F}$ were $0.12 \mathrm{~h}, 1.62 \mathrm{~h}, 0.39 \mathrm{~h}, 5.71 \mathrm{\mu g} / \mathrm{mL}$ and $74.2 \%$, respectively. The MICs of cefquinome against black swans $E$. coli ranged from 0.03 to $8 \mu \mathrm{g} / \mathrm{mL}$, with $\mathrm{MIC}_{50}$ and $\mathrm{MIC}_{90}$ of 0.06 and $0.5 \mu \mathrm{g} / \mathrm{mL}$, respectively. The PK/PD cutoff of cefquinome against $E$. coli was determined to be $0.2 \mu \mathrm{g} / \mathrm{mL}$. Monte Carlo simulation showed that the nominal dose regimen $(2 \mathrm{mg} / \mathrm{kg} / 24 \mathrm{~h}$ ) could not achieve a satisfactory probability of target attainment (PTA) for $\% \mathrm{~T}_{\text {MIC }} \geq 50 \%$, indicating a risk of treatment failure and the development of potential drug resistance.

Conclusions: The current daily dosage of cefquinome when divided into 12-h interval (1 mg/kg/12 h) may be effective for the treatment of $E$. coli infections with an MIC $\leq 0.5 \mu \mathrm{g} / \mathrm{mL}$.
\end{abstract}

Keywords: Cefquinome, Black swans, Pharmacokinetics, Monte Carlo analysis

\section{Background}

The black swan (Cygnus atratus) is a large black-feathered waterbird which breeds mainly in New Zealand, Australia and adjacent coastal islands with nomadic migration patterns dependent on climatic conditions. As a popular ornamental bird, black swans have been introduced into numerous countries and have formed stable populations in zoological gardens [1]. In general, clinical bacterial infections caused by Enterobacteriaceae are common in waterfowl [2]. Additionally, Escherichia coli, Salmonella spp. and Campylobacter spp. infections can have serious

\footnotetext{
* Correspondence: dhao138@126.com

${ }^{1}$ Key Laboratory of Aquatic Product Processing, Ministry of Agriculture, Guangzhou, People's Republic of China

${ }^{2}$ Laboratory of Quality \& Safety Risky Assessment for Aquatic Product on

Storage and Preservation, Guangzhou, People's Republic of China

Full list of author information is available at the end of the article
}

detrimental on waterfowl populations and pose a potential threat to human public health as well. A recent study has reported the emergence of carbapenem and colistinresistant E.coli isolates co-carrying $b l a_{\mathrm{NDM}-5}$ and $m c r-1$ genes in the fowls [3], indicating the possible spread and prevalence of such resistant strains through the food chain and migration of wild birds.

Cefquinome is the 4th generation cephalosporin antibiotic developed solely for veterinary use and has been approved for the treatment of many diseases including respiratory tract disease, foot rot in cattle, calf septicemia, metritis-mastitis-agalactia syndrome in sows, foal septicemia and respiratory diseases in horses [4]. Cefquinome is routinely used at a single dose of $2 \mathrm{mg} / \mathrm{kg} \mathrm{BW}$ once-daily [5]. The advantages of cefquinome include broad-spectrum antimicrobial activity, highly stable 
against $\beta$-lactamases, enhanced potency and the ability to penetrate easily into Gram-negative bacterium [6]. Previous pharmacokinetic studies of cefquinome have been conducted in various species including pigs, cattle, beagle dogs, wild boars and ducks [7-11]. However, no relavant study regarding administration of cefquinome in wild animals was reported, and most previous studies were focused on the characteristics of drug disposition without regard to the appropriate dose regimen assessment for therapeutic use of cefquinome. Here we report, to the best of our knowledge, for the first time cefquinome PK properties and dose regimens assessment in wild birds.

In the present study, we present the PK profile and bioavailability of cefquinome in black swans. The MICs of cefquinome against $49 \mathrm{E}$. coli isolates from black swans were also determined. In addition, Monte Carlo analysis was performed to derive the corresponding daily dose regimens required to achieve the specific activity for various MIC breakpoints based on the determined PK parameters in black swans, the MIC distribution and the reported PD targets [12]. These results may provide fundamental data for the assessment of clinical efficacy of cefquinome and suggestions for a more rational dose regimen in black swans expected of having $E$. coli infections.

\section{Methods}

\section{Animals and experimental design}

Twelve healthy black swans weighting $5.14 \pm 0.79 \mathrm{~kg}$ were divided equally into two groups. Each group randomly included three males and three females. Swans in each group received cefquinome (cefquinome sulfate injection, $40 \mathrm{mg} / \mathrm{mL}$, Qilu Animal Health Products Co., Ltd., Jinan, China) at a single dose of $2 \mathrm{mg} / \mathrm{kg} / 24 \mathrm{~h} \mathrm{BW}$ by IV (brachial vein) or IM (chest muscle) injection. The black swans used in this study were kindly provided by the Lv-Yuan Rare Bird Farm (Shangdong, China). All birds were raised in accordance with the National Standards for Laboratory Animals of China (GB 149252010), allowed ad libitum access to water and antibacterial-free feedstuffs. The animal experimental protocol was approved by the Committee on the Ethics of animals of South China Sea Fisheries Research Institute and the Institutional Animal Care and Use Committee of Lv-Yuan Rare Bird Farm.

\section{Sample collection and analysis}

Blood $(0.5 \mathrm{~mL})$ was collected from the contralateral brachial vein with heparin sodium before and at $0.083,0.25$, $0.5,1,2,3,4,6,8,12$ and $24 \mathrm{~h}$ following IV or IM administration. Plasma samples were then immediately isolated by centrifugation at $4000 \mathrm{rpm}$ for $10 \mathrm{~min}$ and stored at $-80{ }^{\circ} \mathrm{C}$ until further analysis.
A $0.2 \mathrm{~mL}$ aliquot of plasma sample was transferred into a capped centrifuge tube, and then mixed with $0.2 \mathrm{~mL}$ of acetonitrile. After vortexing (30 s) and centrifuging $(12,000 \mathrm{rpm}, 10 \mathrm{~min})$, the supernatant was filtered through a $0.22 \mu \mathrm{m}$ nylon syringe filter and collected into a sample vial for concentration determination. The plasma cefquinome concentrations were determined using a modified high performance liquid chromatography tandem mass spectrometry (HPLC-MS/ MS) method as our previously reported [9] (details are given in Additional file 1). The calibration standards in the linear range of $0.01-0.5 \mu \mathrm{g} / \mathrm{mL}$ were produced by working solutions spiked in blank plasma after extraction. All samples that had concentrations above $0.5 \mu \mathrm{g} /$ $\mathrm{mL}$ were diluted proportionally with the control plasma prior to extraction with acetonitrile. The limit of detection (LOD) and quantification (LOQ) for cefquinome in plasma were set according to signal-to-noise $(\mathrm{S} / \mathrm{N})$ ratio of 3:1 and 10:1, respectively. The analytical method was validated by assessing extraction efficiency and interand intra-day reproducibility at drug concentrations of $0.01,0.1$ and $0.5 \mu \mathrm{g} / \mathrm{mL}$.

\section{Pharmacokinetic analysis}

Pharmacokinetic parameters of cefquinome were estimated by a compartmental method using WinNonlin software (version 6.1, Pharsight, St. Louis, MO, USA). The best-fitting model required to describe cefquinome timeconcentration curves for each swan was determined by application of the weighed residual sums of square and Akaike Information Criterion (AIC) methods [13]. The time-concentration of IV route was best fitted in WinNonlin program using a two-compartment model as presented in Model 7: Concentration $(\mathrm{T})=\mathrm{Ae}^{-\alpha \cdot \mathrm{T}}+B \mathrm{~B}^{-\beta \cdot \mathrm{T}}$. The IM route was best fitted in WinNonlin program using a one-compartment model with the first-order absorption as presented in Model 3: Concentration $(\mathrm{T})=\frac{\text { Dose } \cdot K a}{\mathrm{~V}_{\mathrm{d}}(\mathrm{Ka}-\mathrm{Ke})} \mathrm{e}^{-\mathrm{Ke} \cdot \mathrm{T}}-e^{-\mathrm{Ka} \cdot \mathrm{T}}$. For IV dosing, the distribution and elimination half-lives were estimated as $\mathrm{T}_{1 / 2 \alpha}=0.693 / \alpha$ and $\mathrm{T}_{1 / 2 \beta}=0.693 /$ $\beta$, respectively. The half-lives of the first-order absorption and elimination after IM injection were correspondingly calculated as $\mathrm{T}_{1 / 2 \mathrm{Ka}}=0.693 / \mathrm{Ka}$ and $\mathrm{T}_{1 / 2 \mathrm{Ke}}=0.693 / \mathrm{Ke}$. The other $\mathrm{PK}$ parameters, peak plasma concentration $\left(\mathrm{C}_{\max }\right)$, the time to $\mathrm{C}_{\max }\left(\mathrm{T}_{\max }\right)$, the apparent steady-state volume of distribution $\left(\mathrm{V}_{\mathrm{ss}}\right)$, total area under time-concentration curve (AUC) and total body clearance $\left(\mathrm{Cl}_{\mathrm{B}}\right)$ were also calculated in WinNonlin software. The bioavailability (F\%) was calculated according to the standard equations as follows [14]: $\mathrm{F}=\frac{\mathrm{AUC}_{\mathrm{IM}}}{\mathrm{AUC}_{\mathrm{IV}}} \times 100 \%$. All PK parameters were presented as mean \pm SD values. 


\section{MIC determination}

A total of $49 \mathrm{E}$. coli strains were obtained from more than 300 faecal swabs of black swans breeded in five different separated populations between 2014 and 2015. The MICs of cefquinome for these $E$. coli isolates were determined using the standard CLSI microdilution method [15]. The MICs for $50 \%$ and $90 \%$ of the isolates $\left(\mathrm{MIC}_{50}\right.$ and $\mathrm{MIC}_{90}$, respectively) were calculated accordingly.

\section{Monte Carlo analysis and dose assessment}

For $\beta$-lactam antibiotics acting by the time-dependent killing mechanisms, it is commonly recommended that the duration of time that drug levels exceed the MIC $\left(\% \mathrm{~T}_{\mathrm{MIC}}\right)$ should be at least $50 \%$ and possibly more than $80 \%$ of the dosing interval to ensure an appropriate bactericidal effect [12]. To further assess the recommended dose regimens of cefquinome in black swans against $E$. coli, a 10,000-subject Monte Carlo analysis was conducted using the Crystal Ball Professional software (version 7.2.2; Oracle Corporation), based on the current PK parameters, MIC distribution and the PD targets $\left(\% \mathrm{~T}_{\mathrm{MIC}}>50\right.$ or $\left.80 \%\right)$.

The $\% \mathrm{~T}_{\text {MIC }}$ values after IM injection was calculated using the following equation: Concentration $(\mathrm{t})=$ $\frac{\text { Dose } \cdot \mathrm{Ka} \cdot \mathrm{F}}{\mathrm{V}_{\mathrm{d}}(\mathrm{Ka}-\mathrm{Kel})} \mathrm{e}^{-\mathrm{Ke} \cdot \mathrm{t}}-\mathrm{e}^{-\mathrm{Ka} \cdot \mathrm{t}}$, where concentration is the MIC, $\mathrm{V}_{\mathrm{d}}$ is the apparent volume of distribution, $\mathrm{F}$ is bioavailability, $\mathrm{Ka}$ is constant of absorption rate and $\mathrm{Ke}$ is constant of elimination rate for IM administration. All PK parameters were assumed to be normally distributed in the form of mean and standard deviation (Table 1). In order to obtain a unimodal distribution, the two isolates with a MIC of $8 \mu \mathrm{g} / \mathrm{mL}$ were consequently removed, and the $\log _{2}$-transformed MIC distribution of the other 47 isolates was submitted to the non-linear least squares regression and standard goodness-of-fit test. The probability of attaining the $\% \mathrm{~T}_{\mathrm{MIC}}$ targets at the specific MICs was accordingly calculated. The PK/PD cutoff $\left(\mathrm{CO}_{\mathrm{PD}}\right)$ is defined as the $\mathrm{MIC}$, at which the PTA for $\% \mathrm{~T}_{\mathrm{MIC}}$ target $(50 \%)$ was equal to $90 \%$ under the current clinical recommended dose ( $2 \mathrm{mg} / \mathrm{kg} / 24 \mathrm{~h}$ ). For calculation of daily dose regimens, the $\mathrm{MIC}$ was defined as a single value ranging from 0.03 to $8 \mu \mathrm{g} / \mathrm{mL}$. Scenarios were simulated separately for a single IM injection of cefquinome from 0 to $265 \mathrm{mg} / \mathrm{kg}$ with 24$\mathrm{h}$ or $12-\mathrm{h}$ intervals. The precise recipes of cefquinome required to achieve the specific activity $\left(\% \mathrm{~T}_{\mathrm{MIC}}>50\right.$ or $80 \%)$ against E. coli isolate at each MIC in black swans were also estimated based on PK data, Monte Carlo analysis and the equation mentioned above.

\section{Results}

Cefquinome concentration assay in swan plasma

The matrix-matched calibration curve was linear between 0.01 and $0.5 \mu \mathrm{g} / \mathrm{mL}$, with a coefficient of
Table 1 Mean \pm SD values of the pharmacokinetic parameters of cefquinome in black swans after IV and IM administration at a dose of $2 \mathrm{mg} / \mathrm{kg} \mathrm{BW}$

\begin{tabular}{llll}
\hline Parameter & Unit & $\mathrm{IV}$ & $\mathrm{IM}$ \\
\hline $\mathrm{Ka}$ & $1 / \mathrm{h}$ & - & $5.64 \pm 3.07$ \\
$\mathrm{~A}$ & $\mu \mathrm{g} / \mathrm{mL}$ & $10.7 \pm 4.97$ & - \\
$\mathrm{a}$ & $1 / \mathrm{h}$ & $2.27 \pm 0.23$ & - \\
$\mathrm{Kel}$ & $1 / \mathrm{h}$ & - & $0.43 \pm 0.03$ \\
$\mathrm{~B}$ & $\mu \mathrm{g} / \mathrm{mL}$ & $4.20 \pm 1.91$ & - \\
$\beta$ & $1 / \mathrm{h}$ & $0.42 \pm 0.09$ & - \\
$\mathrm{V}_{\mathrm{sS}}$ & $\mathrm{L} / \mathrm{kg}$ & $0.32 \pm 0.17$ & - \\
$\mathrm{T}_{1 / 2 \mathrm{Ka}}$ & $\mathrm{h}$ & - & $0.12 \pm 0.04$ \\
$\mathrm{~T}_{1 / 2 \mathrm{a}}$ & $\mathrm{h}$ & $0.31 \pm 0.03$ & - \\
$\mathrm{T}_{1 / 2 \mathrm{Ke}}$ & $\mathrm{h}$ & - & $1.62 \pm 0.11$ \\
$\mathrm{~T}_{1 / 2 \beta}$ & $\mathrm{h}$ & $1.69 \pm 0.85$ & - \\
$\mathrm{T}_{\max }$ & $\mathrm{h}$ & - & $0.39 \pm 0.19$ \\
$\mathrm{C}_{\max }$ & $\mu \mathrm{g} / \mathrm{mL}$ & - & $5.71 \pm 1.43$ \\
$\mathrm{AUC}$ & $\mu \mathrm{g} \cdot \mathrm{h} / \mathrm{mL}$ & $16.5 \pm 4.92$ & $12.17 \pm 4.32$ \\
$\mathrm{Cl}_{\mathrm{B}}$ & $\mathrm{L} / \mathrm{kg} \cdot \mathrm{h}$ & $0.13 \pm 0.04$ & - \\
$\mathrm{F}$ & $\%$ & - & $74.2 \pm 26.3$ \\
\hline $\mathrm{A}$ & $\%$ & &
\end{tabular}

A, zero-time intercept of the distribution slope in the compartment model; $B$, zero-time inter of decline in plasma concentration of drug; $a$, distribution rate constant; $\beta$, elimination constant; $\mathrm{Ke}$, constant of elimination rate; $\mathrm{Ka}$, constant of absorption rate; $T_{1 / 2 \mathrm{Kel}}$, elimination half-life; $T_{1 / 2 a}$, the distribution half-life; $T_{1 / 2 \beta}$, the half-life of elimination; $T_{1 / 2 K a}$ absorption half-life; $V_{s s,}$ the apparent steady-state volume of distribution; $\mathrm{Cl}_{\mathrm{B}}$, total body clearance; $\mathrm{AUC}$, total area under the concentration-time curve from zero to infinity; $T_{\max }$, time to $C_{\max }$ from time zero; $C_{\max }$, peak plasma concentration; $F$, bioavailability

determination $\left(\mathrm{R}^{2}\right)$ of 0.998 . The LOQ and LOD were 0.01 and $0.005 \mu \mathrm{g} / \mathrm{mL}$, respectively. Mean extraction recoveries from the five replicate assays were $88.9 \pm 7.96 \%$, $95.2 \pm 7.20 \%$ and $98.3 \pm 7.97 \%$ at spiked drug concentrations of $0.01,0.1$, and $0.5 \mu \mathrm{g} / \mathrm{mL}$, respectively. The intraday coefficients of variation for replicate control samples $(n=5)$ within these concentration ranges varied from 1.52 to $5.69 \%$, and the interday coefficients of variation ranged from 5.96 to $7.18 \%$.

\section{Pharmacokinetics of cefquinome in plasma}

No adverse effect or intolerance was observed during the entire experiment. The plasma time-concentration profiles are plotted in Fig. 1, and the corresponding PK parameters are summarized in Table 1. Cefquinome exhibited a biphasic decline and showed the best fit to a two-compartmental open model after IV dosing in black swans. The distribution half-life $\left(\mathrm{T}_{1 / 2 \alpha}\right)$ and elimination half-life $\left(\mathrm{T}_{1 / 2 \beta}\right)$ were $0.31 \pm 0.03 \mathrm{~h}$ and $1.69 \pm 0.85 \mathrm{~h}$, respectively. After IM injection, the drug time-concentration data was best described by a onecompartment model with first-order absorption. Cefquinome was absorbed rapidly with an absorption 


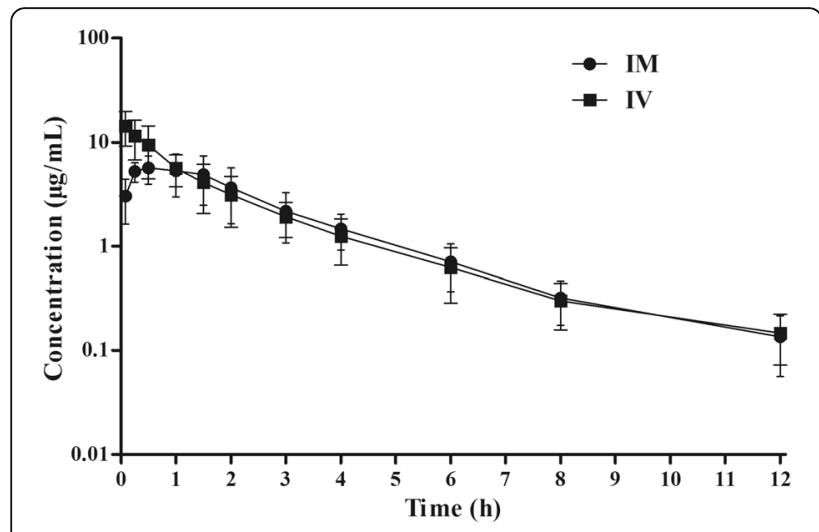

Fig. 1 Semi-logarithmic plot of plasma concentration-time profiles of cefquinome after IV and IM administration at a single dose of $2 \mathrm{mg} / \mathrm{kg}$ BW. Values are mean $\pm \mathrm{SD}(n=6)$

half-life $\left(\mathrm{T}_{1 / 2 \mathrm{Ka}}\right)$ of $0.12 \mathrm{~h}$. The peak concentration $\left(\mathrm{C}_{\max } ; 5.71 \mu \mathrm{g} / \mathrm{mL}\right)$ was achieved at $0.39 \mathrm{~h}$, and the bioavailability was $74.2 \pm 26.3 \%$ after IM injection. No drug was detected at $24 \mathrm{~h}$ after cefquinome administration.

\section{MIC distribution}

As shown in the primitive cefquinome MIC distribution in Fig. 2a, the MICs for cefquinome against $49 \mathrm{E}$. coli strains isolated from black swans were in the range of 0.03 to $8 \mu \mathrm{g} / \mathrm{mL}$. The $\mathrm{MIC}_{50}$ and $\mathrm{MIC}_{90}$ were determined to be 0.063 and $0.5 \mu \mathrm{g} / \mathrm{mL}$, respectively (Additional file 2 : Table S1). The distribution percentage at each MIC $(0.03$, $0.06,0.13,0.25,0.5,1,2$ and $8 \mu \mathrm{g} / \mathrm{mL}$ ) was $26.5 \%, 42.9 \%$, $14.3 \%, 6.1 \%, 2.0 \%, 2.0 \%, 2.0 \%$ and $4.1 \%$, respectively. In the fitted $\log _{2}$-transformed MIC distribution of the 47 isolates, the best fit for the unimodal population was found $\left(R^{2}=0.85\right)$ when presumed MIC distribution was defined as being between 0.03 and $2.0 \mu \mathrm{g} / \mathrm{mL}$.

\section{Monte Carlo analysis and dose assessment}

The PTA values of cefquinome administered at single dose of $2 \mathrm{mg} / \mathrm{kg} / 24 \mathrm{~h}$ against $E$. coli at each MIC were presented in Fig. 3. When MIC of E. coli was below $0.2 \mu \mathrm{g} / \mathrm{mL}$, the PTA for achieving $\% \mathrm{~T}_{\mathrm{MIC}}>50 \%$ was as high as $90.2 \%$. Therefore, the PK/PD cutoff of cefquinome against $49 \mathrm{E}$. coli isolates obtained in our study was $0.2 \mu \mathrm{g} / \mathrm{mL}$. In addition, the calculated daily
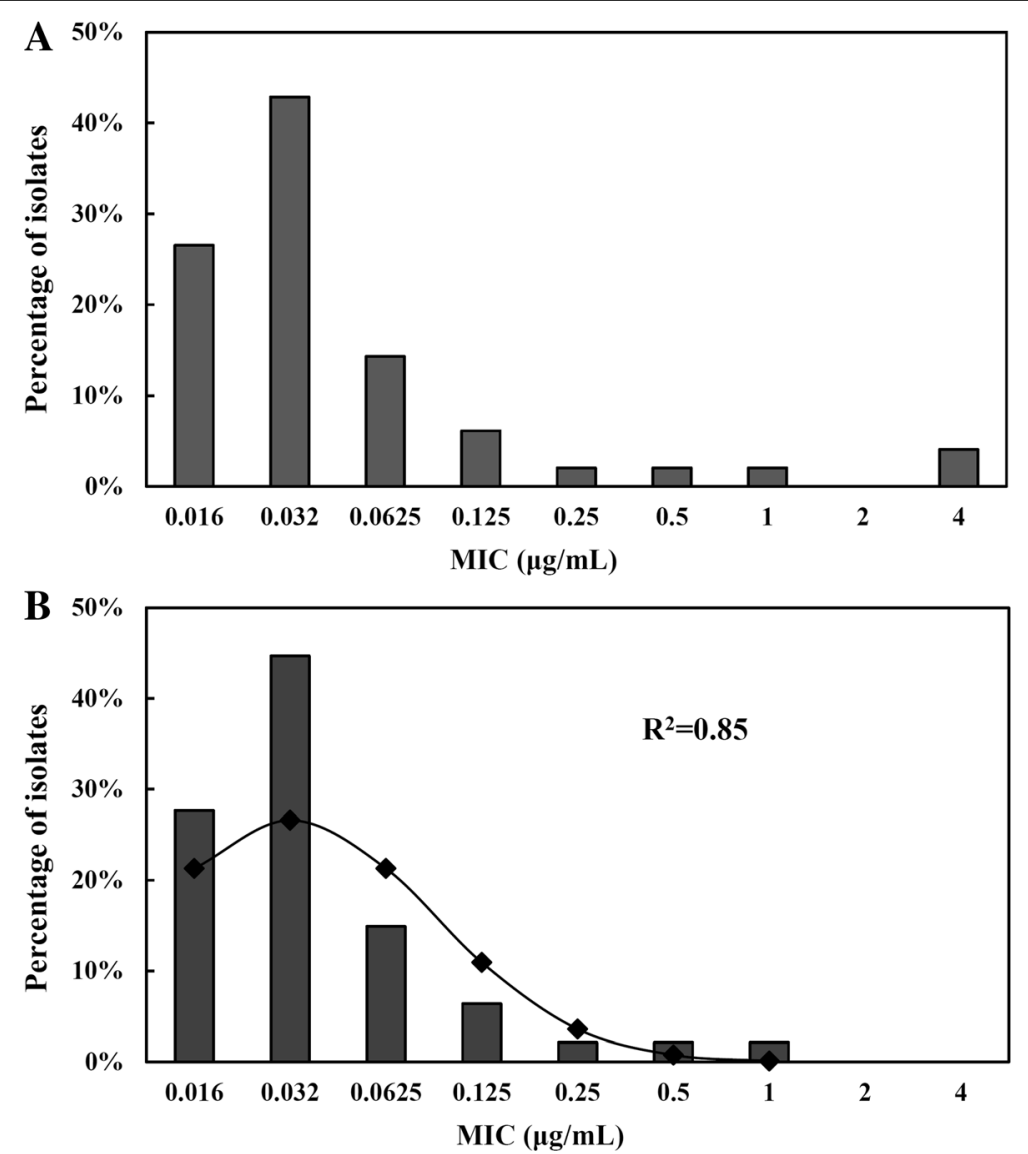

Fig. 2 The MIC distribution of cefquinome against E. coli isolates from black swans. a Primary MIC distribution of 49 E. coli isolates; (b) Fitted MIC distribution of the estimated $47 \mathrm{E}$. coli isolates after the goodness-of-fit tests and nonlinear least-squares regression. The lines indicate fitted theoretical normal distribution values 


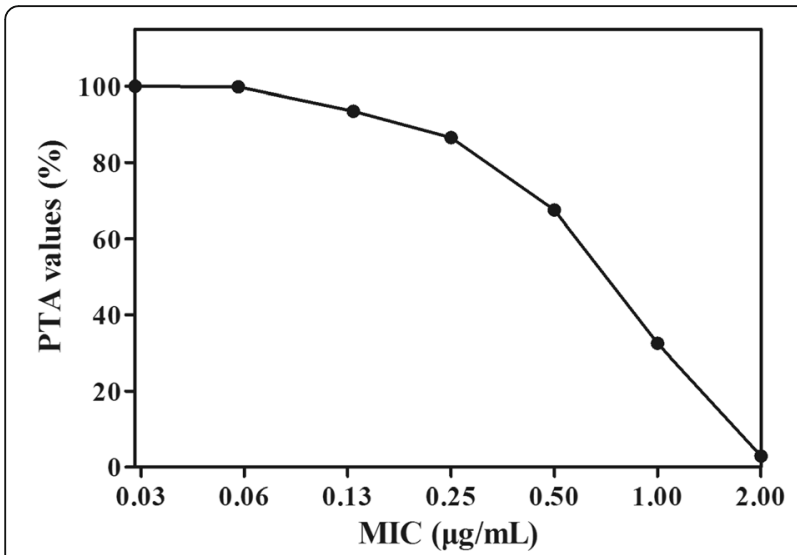

Fig. 3 The probability of target attainment (PTA) of cefquinome treated with the current clinical dose regimen (2 mg/kg/24 h) against E. coli at each MIC value

dosages of cefquinome required to achieve the specific activity $\left(\% \mathrm{~T}_{\mathrm{MIC}}>50 \%\right.$ or $\left.80 \%\right)$ against E. coli isolates with different MICs in black swans were summarized in Table 2. A simulated dose regimen (1.86 $\mathrm{mg} / \mathrm{kg} / 24 \mathrm{~h})$ would be only therapeutically effective against $E$. coli with $\mathrm{MIC} \leq 0.125 \mu \mathrm{g} / \mathrm{mL}$ in black swans. However, the similar daily total dose (1.94 $\mathrm{mg} / \mathrm{kg}$ ) may achieve a successful therapy for $E$. coli with a MIC of $\leq 0.5 \mu \mathrm{g} / \mathrm{mL}$ after splitting the dose into 12 -h intervals $(0.97 \mathrm{mg} / \mathrm{kg} / 12 \mathrm{~h})$. Similarly, as shown in Fig. 4, for the used E. coli MIC distribution in the present study, a PTA of $11.2 \%$ for $\% \mathrm{~T}_{\mathrm{MIC}} \geq 80 \%$ was acquired when cefquinome administered at $2 \mathrm{mg} /$ $\mathrm{kg}$ once-daily, while $91.9 \%$ could be achieved if the same dose given at $12-\mathrm{h}$ intervals $(1 \mathrm{mg} / \mathrm{kg} / 12 \mathrm{~h})$.

\section{Discussion}

This study was the first of its kind to investigate PK of cefquinome applied in wild birds. The elimination half- life $\left(\mathrm{T}_{1 / 2 \beta}\right)$ of cefquinome after IV administration was $1.69 \mathrm{~h}$, which was similar to those values reported in chickens $(1.29 \mathrm{~h})$ and ducks $(1.57 \mathrm{~h})$, indicating a relatively short drug persistence in black swans $[11,16]$. However, an evidently shorter elimination half-life was observed in beagle dogs $(0.98 \mathrm{~h})$ or sheep $(0.78 \mathrm{~h})[9,17]$. Similarly, a more rapid absorption $\left(\mathrm{T}_{1 / 2 \mathrm{Ka}}\right)$ of cefquinome after IM injection were acquired in black swans $(0.12 \mathrm{~h})$, chickens $(0.07 \mathrm{~h})$ and ducks $(0.12 \mathrm{~h})$ compared with in mammals such as piglets $(0.41 \mathrm{~h})$, sheep $(0.31 \mathrm{~h})$ and camels (4.35 h) [11, 17-20]. This PK property represented a shorter duration for the drug to reach systemic circulation and to more rapidly establish of effective drug concentration in birds.

The diffusion of cefquinome in the body tissues of different animal species is very small. In this study, barely $0.32 \mathrm{~L} / \mathrm{kg}$ of $\mathrm{V}_{\text {ss }}$ was obtained in black swans similar to $0.25 \mathrm{~L} / \mathrm{kg}$ in piglets and $0.19 \mathrm{~L} / \mathrm{kg}$ in pigs $[21,22]$. According to the CVMP report, an attenuated distribution of cefquinome to intracellular spaces was due to low fat solubility and that it acts as an organic acid with a low $\mathrm{pKa}$ of 2.51 or 2.91 [5]. In addition, total body clearance $\left(\mathrm{Cl}_{\mathrm{B}}\right)$ in black swans was determined to be $0.13 \pm 0.04 \mathrm{~L} / \mathrm{kg} \cdot \mathrm{h}$ in this study, which is similar to $0.18 \mathrm{~L} / \mathrm{kg}$ in rabbits or $0.12 \mathrm{~L} / \mathrm{kg}$ in horse but lower than the corresponding value of $0.26 \mathrm{~L} / \mathrm{kg}$ in piglets $[18,23,24]$.

As an animal-specific cephalosporin, cefquinome has been widely employed in veterinary medicine due to excellent antimicrobial activity. Cefquinome is considered to be a time-dependent antimicrobial agent, and $\% \mathrm{~T}_{\mathrm{MIC}}$ is the dominant PK/PD index correlated with the therapeutic efficacy [25]. The previous PK/PD studies in animal infection models have demonstrated that drug levels of $\beta$-lactam antibiotics needed to exceed the MIC for $36 \%$ to $40 \%$ of dosing interval to exert an in vivo bacteriostatic effect against Enterobacteriaceae [26]. In general, the magnitude of $\% \mathrm{~T}_{\mathrm{MIC}}$ to ensure a significant

Table 2 Calculated total daily dose of cefquinome required to achieve the specific activity (\%T isolates from black swans with diverse MIC values

\begin{tabular}{|c|c|c|c|c|}
\hline \multirow[t]{2}{*}{ MIC $(\mu \mathrm{g} / \mathrm{mL})$ for $E$. coli isolates } & \multicolumn{4}{|c|}{$\begin{array}{l}\text { Total daily dose }(\mathrm{mg} / \mathrm{kg}) \text { of cefquinome required to achieve } \\
\% \mathrm{~T}_{\text {MIC }}>50 \%\end{array}$} \\
\hline & 24-h interval & 12-h intervals & 24-h interval & 12-h intervals \\
\hline 0.031 & 0.45 & 0.14 & 3.88 & 0.38 \\
\hline 0.063 & 0.89 & 0.24 & 7.95 & 0.72 \\
\hline 0.125 & 1.86 & 0.48 & 16.4 & 1.68 \\
\hline 0.25 & 3.25 & 0.98 & 33.7 & 2.96 \\
\hline 0.5 & 7.38 & 1.94 & 67.3 & 6.54 \\
\hline 1 & 14.6 & 3.86 & 132.7 & 12.9 \\
\hline 2 & 29.7 & 7.72 & 264.2 & 27.4 \\
\hline 8 & 115.1 & 31.2 & - & 106.6 \\
\hline
\end{tabular}




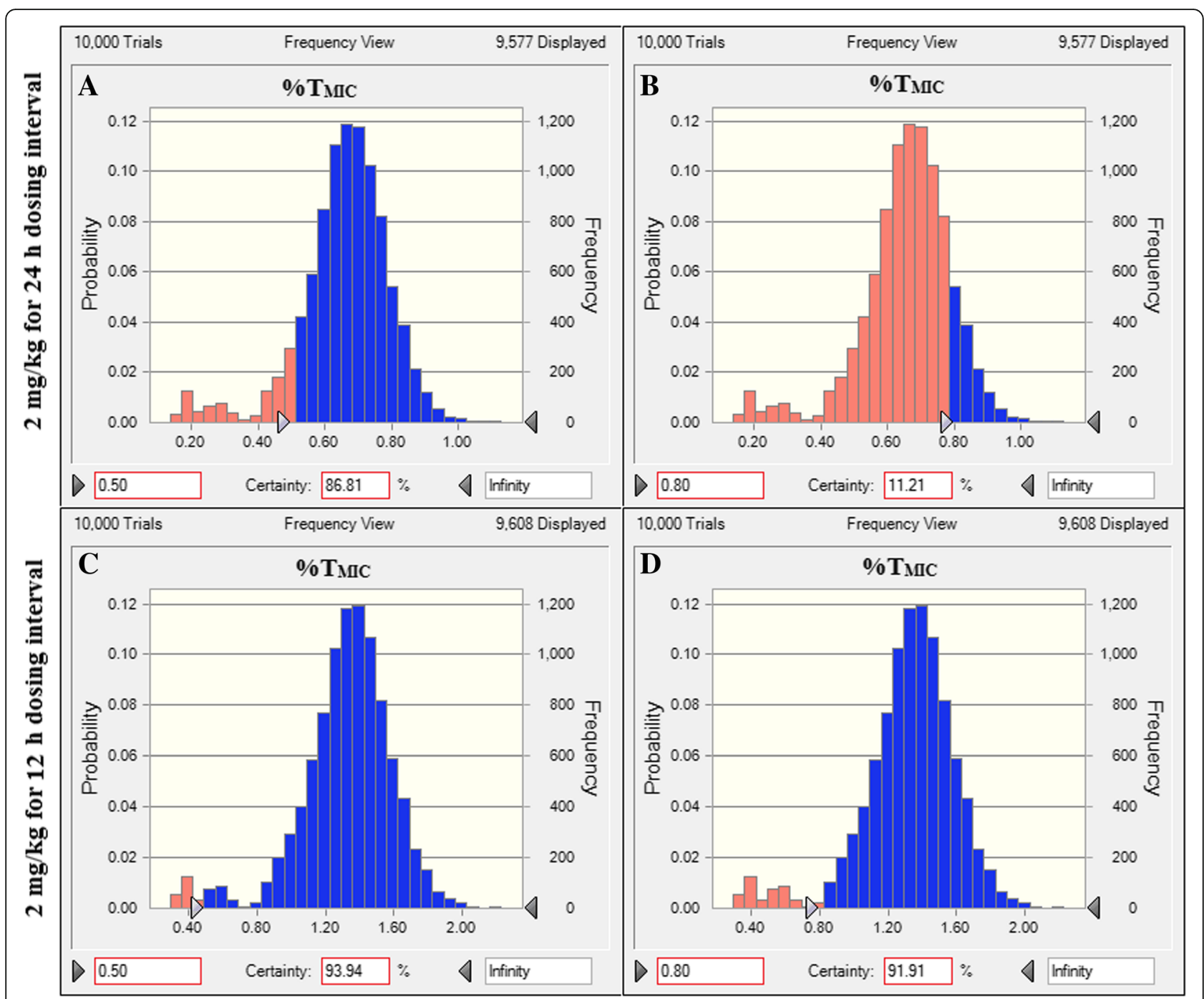

Fig. 4 The probability distribution of the calculated $\% T_{\text {MIC }}$ for cefquinome using a 10,000-subject Monte Carlo analysis based on the measured PK parameters obtained following IM injection at $2 \mathrm{mg} / \mathrm{kg}$ BW with 24-h (a and $\mathbf{b}$ ) and 12-h (c and $\mathbf{d}$ ) dosing interval in black swans and E. coli MIC distribution in this study. The areas of blue columns represent the probability of target attainment (PTA) for $\%$ MIC $\geq 50$ or $80 \%$

bactericidal or virtual elimination effect should be at least $50 \%$ of the recommended dosing interval $[12,27]$.

The PK/PD cutoff is crucial for guiding clinical use of antimicrobials. For most $\beta$-lactam antibiotics, the CLSI and EUCAST have established the $\mathrm{CO}_{\mathrm{PD}}$ from human studies. However, as an important index reflecting the variations in host species $\mathrm{PK}$ and bacterial species MIC distribution, the $\mathrm{CO}_{\mathrm{PD}}$ is normally significantly different between human and animals [28]. Currently, no breakpoint data of cefquinome was established for animal infections caused by $E$. coli. In the present study, the $\mathrm{CO}_{\mathrm{PD}}$ of cefquinome against $E$. coli in black swans was determined to be $0.2 \mu \mathrm{g} / \mathrm{mL}$ at the recommended dose $(2 \mathrm{mg} / \mathrm{kg} / 24 \mathrm{~h}$ ) based on Monte Carlo analysis, which was lower than the EUCAST clinical $\mathrm{CO}_{\mathrm{PD}}$ values of cefotaxime $(2 \mu \mathrm{g} / \mathrm{mL})$, cefpodoxime $(1 \mu \mathrm{g} / \mathrm{mL})$, ceftriaxone
$(2 \mu \mathrm{g} / \mathrm{mL})$, cefixime $(1 \mu \mathrm{g} / \mathrm{mL})$ and ceftibuten $(1 \mu \mathrm{g} / \mathrm{mL})$ against Enterobacteriaceae [29]. However, as only $49 \mathrm{E}$. coli isolates were used in our study due to the limited population of black swans, the relatively conservative $\mathrm{CO}_{\mathrm{PD}}$ should be verified in a larger number of bacteria and clinical practices.

For dosage regimen assessment, Monte Carlo analysis is an important computing tool that is useful to predict the attainment of therapeutic efficacy and determine the $\mathrm{CO}_{\mathrm{PD}}$ according to PK data, MIC distribution and the magnitude of PK/PD indices. As seen in Table 2, the increasing total amount of drug exerted little added therapeutic efficacy even with a considerably high simulated dose. However, after splitting into 12-h intervals, the identical daily dose could achieve a more satisfactory outcome than a single dosing. Therefore, more frequent 
administrations are needed for cefquinome to obtain a longer treatment period in the form of $\% \mathrm{~T}_{\mathrm{MIC}}$. Routinely, a twice-daily schedule is considered a good compliance target in the clinical practice. Based on the current PK study, MIC distribution and specific PD targets, if the dose is given at $1 \mathrm{mg} / \mathrm{kg}$ twice daily, the 10,000-subject Monte Carlo simulation showed that the PTA of $95.9 \%$ and $89.2 \%$ could be achieved for $\% \mathrm{~T}_{\text {MIC }}>50 \%$ and $80 \%$ targets, respectively, against $E$. coli isolates in this study. In addition, taking into account the recently reported $\% \mathrm{~T}_{\mathrm{MIC}}$ target of $51.7 \%$ required to achieve a $2-\log _{10}$ killing effect in murine thigh infection against $E$. coli isolates [27], cefquinome $1 \mathrm{mg} / \mathrm{kg} / 12 \mathrm{~h}$ is estimated to be effective against $E$. coli infection in black swans.

\section{Conclusions}

To our knowledge, it is the first report about the PK and dose assessment study for cefquinome in black swans targeting $E$. coli strains. In the present study, we investigated pharmacokinetics and bioavailability of cefquinome following IV and IM administration in black swans. The MICs of cefquinome against $49 \mathrm{E}$. coli isolates from black swan were also determined. On the basis of PK data, MIC distribution and PD analysis, this study evaluated dose regimens of cefquinome in black swans against E. coli infections. Our findings suggest that the daily dose regimen of cefquinome at $1 \mathrm{mg} / \mathrm{kg} / 12 \mathrm{~h}$ would be appropriate to achieve a satisfactory efficacy in the treatment of infections caused by $E$. coli in black swans.

\section{Additional files}

Additional file 1: LC-MS/MS method. (PDF $42 \mathrm{~kb}$ )

Additional file 2: Table S1. MICs of cefquinome $(\mu \mathrm{g} / \mathrm{mL})$ against $E$. coli strains isolated from black swans. (PDF $47 \mathrm{~kb}$ )

\begin{abstract}
Abbreviations
\% $\mathrm{T}_{\text {MIC: }}$ The duration of time that drug levels exceed the MIC in dosing interval; BW: Bodyweight; CLSI: Clinical and laboratory standards institute; EUCAST: European committee on antimicrobial susceptibility testing; IM: Intramuscular; IV: Intravenous; MIC: Minimal inhibitory concentration; PD: Pharmacodynamic; PK: Pharmacokinetic; PTA: Probability of target attainment
\end{abstract}

\section{Acknowledgements}

We thank the Lv-Yuan Rare Bird Farm for providing the black swans.

\section{Funding}

This work was supported by the Aquatic Products Quality and Safety Special Project of Guangdong (Grant No. GDSCZA2015008). The funder had no role in study design, data collection and analysis, decision to publish, or preparation of the manuscript.

\section{Availability of data and materials}

The datasets used and/or analyzed during the current study are available from the corresponding author on reasonable request.

\section{Authors' contributions}

LDL and $\mathrm{DHZ}$ designed and conducted the experiment. QW and XFW ran the simulations and analyzed the resulting data. $\mathrm{DHZ}$ drafted the manuscript. All authors read, revised and approved the final manuscript.

\section{Ethics approval and consent to participate}

This study was approved by the Committee on the Ethics of Animals of South China Sea Fisheries Research Institute and the Institutional Animal Care and Use Committee of Lv-Yuan Rare Bird Farm. The owners of the rare bird farm consented for their animals to be used in this study. All experiments were conducted using the guidelines of National Standards for Laboratory Animals of China (GB 14925-2010).

\section{Consent for publication}

Not applicable.

\section{Competing interests}

The authors declare that they have no interest.

\section{Publisher's Note}

Springer Nature remains neutral with regard to jurisdictional claims in published maps and institutional affiliations.

\section{Author details}

'Key Laboratory of Aquatic Product Processing, Ministry of Agriculture, Guangzhou, People's Republic of China. ${ }^{2}$ Laboratory of Quality \& Safety Risky Assessment for Aquatic Product on Storage and Preservation, Guangzhou, People's Republic of China. ${ }^{3}$ Fishery Environments and Aquatic Products Quality Inspection \& Testing Center of the Ministry of Agriculture,

Guangzhou, People's Republic of China. ${ }^{4}$ South China Sea Fisheries Research Institute, Chinese Academy of Fishery Sciences, Guangzhou 510300, People's Republic of China

Received: 5 April 2017 Accepted: 24 July 2017

Published online: 28 July 2017

\section{References}

1. Pizzey $G$, Knight $F$. The field guide to the birds of Australia. 9th ed. New York, NY, USA: Harper Collins Publishers, Pymble, NSW, Australia; 2012.

2. Janda JM, Abbott SL. The enterobacteria. 2nd ed. Washington, DC: ASM Press; 2016.

3. Yang RS, Feng Y, Lv XY, Duan JH, Chen J, Fang LX, Xia J, Liao XP, Sun J, Liu YH. Emergence of NDM-5 and MCR-1-producing Escherichia Coli clone ST648 and ST156 from a single Muscovy duck (Cairina Moschata). Antimicrob Agents Chemother. 2016;60(11):6899-902.

4. Limbert M, Isert D, Klesel N, Markus A, Seeger K, Seibert G, Schrinner E. Antibacterial activities in vitro and in vivo and pharmacokinetics of cefquinome (HR 111V), a new broad-spectrum cephalosporin. Antimicrob Agents Chemother. 1991;35(1):14-9.

5. Committee for Medicinal Products for Veterinary Use (CVMP). Cefquinome. Summary report. EMEA/MRL/005/95. London: European Medicines Agency (EMA): 1995.

6. Dumka VK, Dinakaran V, Ranjan B, Rampal S. Comparative pharmacokinetics of cefquinome following intravenous and intramuscular administration in goats. Small Rumin Res. 2013;113(1):273-7.

7. Zhao DH, Zhang CY, Zhang Z, Liu ZC, Liu BT, Yu JJ, Guo JP, Deng H, Liu YH. Population pharmacokinetics of cefquinome in pigs. J Vet Pharmacol Ther 2013;36(4):313-9.

8. Shan $\mathrm{Q}$, Yang F, Wang J, Ding H, He L, Zeng Z. Pharmacokinetic/ pharmacodynamic relationship of cefquinome against Pasteurella multocida in a tissue-cage model in yellow cattle. J Vet Pharmacol Ther. 2014;37(2):178-85.

9. Zhou YF, Zhao DH, Yu Y, Yang X, Shi W, Peng YB, Liu YH. Pharmacokinetics, bioavailability and PK/PD relationship of cefquinome for Escherichia Coli in beagle dogs. J Vet Pharmacol Ther. 2015;38(6):543-8.

10. Liu B, Zhang C, Zhang X, Yang S, Yu J, Sun J, Liu Y. Pharmacokinetics and bioavailability of cefquinome in crossbred wild boars. J Vet Pharmacol Ther. 2012:35(6):611-4.

11. Yuan L, Sun J, Wang R, Sun L, Zhu L, Luo X, Fang B, Liu Y. Pharmacokinetics and bioavailability of cefquinome in healthy ducks. Am J Vet Res. 2011;72(1):122-6. 
12. Toutain PL, Lees P. Integration and modelling of pharmacokinetic and pharmacodynamic data to optimize dosage regimens in veterinary medicine. J Vet Pharmacol Ther. 2004;27(6):467-77.

13. Yamaoka K, Nakagawa T, Uno T. Application of Akaike's information criterion (AIC) in the evaluation of linear pharmacokinetic equations. J Pharmacokinet Biopharm. 1978;6(2):165-75.

14. Toutain PL, Bousquet-Melou A. Bioavailability and its assessment. J Vet Pharmacol Ther. 2004;27(6):455-66.

15. Clinical and Laboratory Standards Institute (CLSI). Performance standards for antimicrobial disk and dilution susceptibility tests for bacteria isolated from animals; approved standard-Third Edition. Wayne: CLSI document M31-A3; 2008.

16. Xie W, Zhang X, Wang T, Du S. Pharmacokinetic analysis of cefquinome in healthy chickens. Br Poult Sci. 2013;54(1):81-6.

17. Uney K, Altan F, Elmas M. Development and validation of a highperformance liquid chromatography method for determination of cefquinome concentrations in sheep plasma and its application to pharmacokinetic studies. Antimicrob Agents Chemother. 2011;55(2):854-9.

18. Li XB, Wu WX, Su D, Wang ZJ, Jiang HY, Shen JZ. Pharmacokinetics and bioavailability of cefquinome in healthy piglets. J Vet Pharmacol Ther. 2008;31(6):523-7.

19. El-Gendy AAM, Tohamy MA, Radi AM. Pharmacokinetic profile and some pharmacodynamic aspects of cefquinome in chickens. Beni-Suef Vet Med J. 2009:19:33-7.

20. Al-Taher AY. Pharmacokinetics of Cefquinome in camels. J Anim Vet Adv. 2010;9(4):848-52.

21. Song IB, Kim TW, Lee HG, Kim MS, Hwang YH, Park BK, Lim JH, Yun HI. Influence of the injection site on the pharmacokinetics of cefquinome following intramuscular injection in piglets. J Vet Med Sci. 2013;75(1):89-92.

22. Zhang BX, Lu XX, Gu XY, Li XH, Gu MX, Zhang N, Shen XG, Ding HZ. Pharmacokinetics and ex vivo pharmacodynamics of cefquinome in porcine serum and tissue cage fluids. Vet J. 2014;199(3):399-405.

23. Allan MJ, Thomas E. Pharmacokinetics of cefquinome after parenteral administration of an aqueous solution in the horse. J Vet Pharmacol Ther. 2003;26(Supplement 1):104

24. Hwang YH, Song IB, Lee HK, Kim TW, Kim MS, Lim JH, Park BK, Yun HI. Pharmacokinetics and bioavailability of cefquinome in rabbits following intravenous and intramuscular administration. J Vet Pharmacol Ther. 2011; 34(6):618-20.

25. Wang J, Shan Q, Ding H, Liang C, Zeng Z. Pharmacodynamics of cefquinome in a neutropenic mouse thigh model of Staphylococcus Aureus infection. Antimicrob Agents Chemother. 2014;58(6):3008-12.

26. Craig WA. Interrelationship between pharmacokinetics and pharmacodynamics in determining dosage regimens for broad-spectrum cephalosporins. Diagn Microbiol Infect Dis. 1995;22(1-2):89-96.

27. Shan Q, Liang C, Wang J, Li J, Zeng Z. In vivo activity of cefquinome against Escherichia Coli in the thighs of neutropenic mice. Antimicrob Agents Chemother. 2014;58(10):5943-6.

28. Craig WA. Pharmacokinetic/pharmacodynamic parameters: rationale for antibacterial dosing of mice and men. Clin Infect Dis. 1998;26(1):1-10. quiz $11-12$

29. EUCAST. The European Committee on Antimicrobial Susceptibility Testing. Breakpoint tables for interpretation of MICs and zone diameters. Version 7.0, 2017. [http://www.eucast.org/clinical_breakpoints].

\section{Submit your next manuscript to BioMed Central and we will help you at every step:}

- We accept pre-submission inquiries

- Our selector tool helps you to find the most relevant journal

- We provide round the clock customer support

- Convenient online submission

- Thorough peer review

- Inclusion in PubMed and all major indexing services

- Maximum visibility for your research

Submit your manuscript at www.biomedcentral.com/submit

) Biomed Central 